\title{
An Inquiry into Child Health and its Determinants: Application of Ordered Probit Model
}

\author{
Nirmal Kumar Raut, PhD $^{1}$ \\ Subodh Kumar Sah Karmayogi
}

\begin{abstract}
This study analyzes determinants of child health 0 to 5 years old and compares those with the determinants of adolescent health 10 to19 years old. The particular focus is to test whether there exists socio-economic inequality and regional disparity in health of children and adolescents. It utilizes third wave of Nepal Living Standard Survey (NLSS-III) and further exploit ordered probit model to analyze the determinants. The results show the absence of socio-economic inequality in child health while sits presence in adolescent health. It is argued that factors other than income or socio-economic status like medical care, child rearing and breastfeeding matter for child health. However, the study finds regional disparity more pronounced in the health of children than adolescents. This difference may be attributed to the low-level of child-centered health awareness, high cost of access to health service facilities, and limited health service facilities specializing on child health in some regions. In addition, the study finds that caste, age of the child, and parental health status as major determinants of child health while age of the adolescent, education, and their parental health status as major determinants of adolescent health. Further, disaggregation of parental health status reveals that mother's health status matter more. Finally, some recommendations are made for improving child health.
\end{abstract}

Key Words: Child, Adolescent, Health, Inequality, Determinants, Nepal.

\section{Introduction}

Infants, children, old-age people, disadvantaged and other minority group of people are often more vulnerable to the problems such as poor health status caused primarily due to poverty and poor social status (Harrington \& Estes, 2007). The multilateral agencies such as the the World Bank (2007), therefore, urges countries to strengthen their health system

1 Dr. Raut is a Lecturer at Central Department of Economics, Tribhuvan University. Email address: nkraut@cedecontu.edu.np.

2 Mr. Karmayogi is an industrial officer at Cottage and Small Scale Industries, Bhaktapur. Email: skarmayogi@gmail.com 
by improving social conditions particularly for poor mothers and children. Accessibility to resources such as income, time, human capital, psychological capital and social capital play a crucial role for child development outcomes such as health, behavior, emotion and cognition(De Maio et al., 2005; Li, McMurray, \& Stanley, 2008). These resources are determined by opportunity structure, social stratification system of society andpolitical economy. This implies that the resource constraints normally restrain the process of child development which has a far-reaching human capital and labor market implications.Children's health affects their ability to succeed in school and engage in other learning opportunities within the contexts of their family, neighborhood, and community(Murphey et al., 2018). University level education, adult health status and entrance into the labor market are largely reduced due to childhood health problems (Contoyannis \& Dooley, 2010). It, therefore, is imperative to understand the major determinants of child development for better targeting the issues that needs particular policy attention. This paper analyzes the determinants of one of the major indicators/ elements of child development i.e., child health.

Although Nepal has made significant improvements in terms of child's health as evident from the decadal comparison of its infant mortality rate (IMR) and child mortality rate (CMR), there is still a significant inequality in child health across various socio-economic groups and geographic areas (Pandey et al., 2013; Sreeramareddy et al., 2013).Using Nepal Demographic Health Services (NDHS) data, Pandey et al.,(2013) show the existence of inequality by ethnicity, geographic area and wealth quintiles in receiving basic vaccinations, vitamin-A supplement for under 5 years and treatment of diarrhea. Likewise, they also reported inequality in prevalence of anemia and stunting. It is, therefore, important to dig further into these determinants of child health in a more robust and analytical way.

This study investigates into the determinants and measures the extent to which these determinants can impact the child health status. The focus is on children aged 0-5 years. The analysis is also extended to cover the children aged 10-19 years to further understand how these variables play role in shaping health status of adolescent. In order to do the analysis, the study uses data from the NLSS - III and exploit ordered probit model to estimate the effects of variables of interest on child health status. Findings of the study reveal the fact that there is no inequality in health incidence across children belonging to various socio-economic groups. However, the studyfinds inequality across regions; children in mid-western and far-western regions have poorer health status as compared to the children in central region. Other important determinants are child's age, parent's health status and caste. It further shows that these later set of determinants except caste also play an important role on the incidence of adolescent health. In addition, the study conveys that the adolescent's school enrollment status is also significantly associated with their health status. However, contrary to the findings of child health status, the study finds that there exists inequality in the incidence of adolescent health status across various socio-economic groups. In particular, the studyexhibits that the adolescents in the lower consumption quintiles have poor health outcome. 
This paper is divided into seven sections. Section-1 introduces the study; Section-2 highlights the institutional aspects of health care system in Nepal; Section-3 reviews the past literature and identifies research gap; Section-4 discusses the data and estimation strategy; Section-5 presents the results; Section-6 discusses the results; and Section-7 concludes with some policy implications.

\section{Institutional Background}

The Constitution of Nepal - 2015 ensures the right to basic health services from the State to all the citizens of the country. After the promulgation of new constitution in 2015 when the country adopted federal structure, Nepal is administratively divided into seven provinces, 77 districts and 753 municipalities. ${ }^{3}$ In the old health system, there were five level of public health care in Nepal. Sub-health post (SHP) was the first contact point for basic health services followed by health post (HP), primary health care centers (PHCCs), district, zonal, regional and central level hospitals. In the new institutional set up, HPs are the first contact point for basic health services and each level above the HP level is a referral point in a network from PHCCs on to primary and secondary level hospitals, and finally to tertiary level hospitals. The objective of this institutional arrangement is to ensure that large number of people can receive health care services and minor treatment in accessible places.

Reduction of child and infant mortality has always been a priority of the Government of Nepal (GoN). Health programmes in Nepal are guided by the National Health Policy-1991 and long term health plans (LTHPs). After the implementation of the first LTHP (19751990), the GoN implemented Second LTHP (1997-2017) that focuses on improving the health status of women and children; the rural population; the poor; the underprivileged; and the marginalized. In this regard, the GoN provides essential health care services to all citizens where safe motherhood and family planning, child health, control of communicable

diseases and strengthening of out-patient care are prioritized. Following are the major health programmes being run by the government for the children:

i. Extended vaccination and vaccination against polio programme,

ii. Measles-rubella vaccine programme for the children of age group from 9 months to below 15 years in all 75 districts,

iii. National polio vaccination programme in all 75 districts,

iv. Community based integrated management of childhood illness (CBIMCI) programme and training about CBIMCI for female health volunteers.

v. Severe Malnutrition Management Programme: Under this programme albendazole tablets are distributed to the government and private school children up to class 10 . Similarly, tetanus vaccination and iron tablets are provided to pregnant women.

3 Previously, the country was divided into 5 development regions, 14 zones, 75 districts, 58 municipalities, 3915 village development committee and nearly 36,000 wards. 


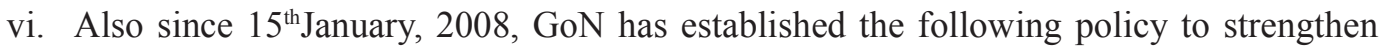
their existing child health services:

a) Free basic health service to all population including medication from village level to central level having capacity of ( $\left.{ }^{3}\right) 25$ beds,

b) Free health treatment to children,

c) Free heart and kidney ailment treatment to children ( $£ 15$ years old),

d) Free distribution of listed medicines like 25 kinds from sub-health-posts, 35 kinds from health posts, and 40 kinds from other level facilities.

vii. National Health Education, Information and Communication Programmes through TV programmes on health related awareness like Aama, Jeevan Chakra, Thorai Vaye Pugisari, health messages on radio, pamphlets, and booklets etc.

At national level, the child health programmes have been successful indicating that child health service delivery managed by the government has been effective. However, this success has not been reflected at household levels due to their different socio-economic, demographic and other characteristics. As mentioned earlier, the study thus intends to identify the major determinants that play an instrumental role in shaping child's health.

\section{Review of Literature}

There exista number of literatures that analyzes the determinants of child health. Majority of these studies are focused on developed countries and exhibit in general consistent impact of family income on child health. The impact, however, vary by age of the children. Apouey and Geoffard (2013) find no correlation between family income and health of British child at ages 0-1 and a large significant and positive effect for children above two.Case, Lubotskyand Paxson (2002) in the USA; Currie and Stabile (2003) in Canada; Khanam, Nghiem, and Connely (2009) in Australia; and Reinhold and Jürges (2012) in Germany exhibit the relationship on similar lines where they find causal effect of family income on child health where the relationship becomes more pronounced as children grow older. They argue that low-income children are more likely to be subject of health shocks. However, the study in Australia further demonstrates that the causal effect disappears after including richer set of controls to address the endogeneity issue. Likewise, Propper, Rigg, and Burgess (2007) find that the relationship between family income and child health becomes insignificant after controlling maternal health whereas Kruk (2013); and Apouey and Geoffard (2013) show that the relationship is significant after controlling for parental health. This shows that the relationship between family income and child health remain ambiguous in developed countries.

There are mixed set of results about the impact of income or expenditure on child health in developing countries.Charmarbagwala et al., (2014)conducts meta-analysis of previous studies in developing countries where they conclude that most of the studies demonstrate negative and significant relationship of income with infant/child mortality 
while positive and significant relationship with nutrition. The paper also reviews few studies of South Asian countries like India, Bangladesh and Pakistan and most of these studies have an expected sign of the effect of income on child health outcomes. However, it is not clear from the paper that what age groups they are referring to and how the impact would vary by age.

Charmarbagwala et al., (2014) also summarizes the results for the effects of gender on mortality and nutrition and finds that almost half of the studies do not find significant effect while remaining half shows mixed impact. In general, it is expected that the parental preference towards boys would reduce the investment on girls which would adversely affect the latter's health status. Likewise, most studies show that location (Rural vs. Urban) does not significantly determine mortality while urban residents are more likely to be nourished. The effects of child's/infant's age on mortality in most studies is shown to be negative i.e. the mortality reduces as the children grow older. This indicates that older children are healthier than the younger ones.

Few studies are carried out in Nepal that analyzes the determinants of child health. Suwal (2001) using Nepal Demographic Health Survey (NDHS)-1991 finds parity (socioeconomic equality), place of residence, immunization and ethnicity have significant effects on infant mortality. There has been not much change in the determinants of infant mortality in Nepal over time. Using NDHS-2011, Khadka et al., (2015) also show that socio-economic status and place of residence as the most important determinants of child mortality in Nepal. In other words, these studies show that the children of lower socioeconomic status and those living in far and mid-western regions experience high infant mortality. This indicates the existence of high socio-economic inequality and regional disparity in child health in Nepal. In addition, studies also show the age and gender of the children, location (Rural v:s Urban), family size and parental health and education are among the other major determinants of child health (Lamichhane et al., 2017; Sah, 2004; and Tiwari, Ausman, \& Agho, 2014).

This paper is novel in following respects: First, only limited literatures are available in South Asia region and Nepal in particular that empirically test the association between child health and its determinants. Second, there is an ambiguity about the role and direction of relationship between income and child health status in the past literature. This study hence will offer external validation to the past studies. Third, unlike previous studies that focus on child aged of 0-5 years, this study extends its analysis to cover the children 10-19 years old. Since there is no particular attention given to the health of adolescence, understanding their health determinants may help draw some policy attention. There are now number of literature which discuss the importance of understanding the health issues of adolescence (Crosby, Santelli, \& DiClemente, 2009; Thapa et al., 2017; and WHO, 2005). Fourth, the study focuses on child health rather than mortality and nutrition. In fact, child health is a proxy measure of mortality and nutrition. Hence, it would validate the findings from previous studies that used mortality and nutrition as their outcome variables. 


\section{Data and Methods}

The paper uses cross-sectional data available from third wave of NLSS-III in 2011 surveyed by the Central Bureau of Statistics, Nepal. The survey provides a bunch of information for this study such as household's socio-economic and demographic characteristics as well as their health and educational status. This survey has information of 5988 households collected from 499 primary sampling units. This study identified 3421 children of $0-5$ years and 6830adolescents of 10-19 years from the survey.

Given that the health status in NLSS-III is measured in an ordinal scale, this study considers an ordered probit model to estimate the relationship between child and adolescent health status and their determinants (Greene \& Hensher, 2009). NLSS-III reports health status as "1" for excellent; "2" for good; " 3 " for fair and " 4 " for poor health status. Due to few observations, fair and poor health statuses are combined and re-categorized into category " 3 " as fair health status. So far as the model is concerned, it comes originally from bio-statistics (Aitchison \& Silvey, 1957) and was introduced in social sciences by two political scientists (McKelvey \& Zavoina, 1975). Accordingly, the ordered response is being expressed as a latent continuous random variable which is a linear combination of some predictors plus a disturbance term that has a standard normal distribution:

$C H S_{i, h}^{*}=\beta_{0}+\sum_{p=1}^{n-1} \beta_{1 p} S E S_{h, p}+\beta_{2} X_{i, h}+L_{l}+\varepsilon_{i . h}, \varepsilon_{i . h \sim}(0,1), \forall i=1 \ldots . \ldots \ldots$

Here, the observed ordinal variable, takes on values 1 to 3 as given following scheme:

$C H S_{i, h}=k \Leftrightarrow \mu_{k-1}<C H S_{i, h}^{*} \leq \mu_{k}$

where, in this case $=1,2,3$. is an ordered response category denoting child/adolescent health status. Equation (2) shows the relationship between the observed changes and the latent continuous variable. represents a particular category $p$ of socio-economic status the households belongs to. is household and child/adolescent characteristics. is location-specific characteristics. is a random error term clustered at household level.

This study categorized socio-economic status based on consumption profile of household. Accordingly, households are divided into five consumption quintiles. This study considers the household in the richest consumption quintile as a reference category and hence did not include in the equation (1). The coefficients on the included socio-economic status variables will yield the measure of whether and by how much the incidence of health vary across various socioeconomic groups. In other words, this measure will also suggest whether there exist any socioeconomic inequality in health status of children and adolescents. Household characteristics include caste / ethnicity, household size and land ownership. Household head characteristics include their age, level of education and gender. Child characteristics include their age, gender and school enrollment status. Locational characteristics include regional dummy, place of residence (rural or urban areas) and a dummy for the nearest health facility if it is located at more than half an hour distance from the households. The coefficients on regional dummies will suggest whether there exists any regional disparity in health incidence. For ethnic background, a categorical variable is created and coded as "1" for Brahmin / Chettri, "2" for Newars; " 3 " for Terai-madhesi and janajati households; and "4" for Dalits, Muslims and other castes. The given Table-1 shows the descriptive statistics of the variables used in the equation (1). 
Table 1: Descriptive Statistics for Child (0-5 years) and Adolescent (10-19 years)

\begin{tabular}{|c|c|c|c|c|}
\hline \multirow{2}{*}{ Variables } & \multicolumn{2}{|c|}{ Age $0-5$ years } & \multicolumn{2}{|c|}{ Age $10-19$ years } \\
\hline & Mean & S.D. & Mean & S.D. \\
\hline \multicolumn{5}{|c|}{ Dep. Variable: Health Status } \\
\hline Excellent $=1$ & 0.639 & 0.480 & 0.666 & 0.472 \\
\hline Good=2 & 0.352 & 0.477 & 0.328 & 0.469 \\
\hline Fair $=3$ & 0.008 & 0.092 & 0.006 & 0.078 \\
\hline \multicolumn{5}{|c|}{ Household(HH) Characteristics } \\
\hline HH own agricultural land (=1) & 0.762 & 0.426 & 0.770 & 0.420 \\
\hline HH consumption per capita (in NRs.) & $29,841.16$ & $24,820.1$ & $36,999.66$ & 33,442 \\
\hline HH size & 6.663 & 3.001 & 5.979 & 2.580 \\
\hline Brahmin / Chettri (=1) & 0.309 & 0.462 & 0.333 & 0.471 \\
\hline $\begin{array}{l}\text { Terai-madhesi and janajati households } \\
(=1)\end{array}$ & 0.426 & 0.494 & 0.421 & 0.494 \\
\hline Newar (=1) & 0.048 & 0.214 & 0.067 & 0.251 \\
\hline Dalit, Muslim and other castes ( $=1$ ) & 0.216 & 0.411 & 0.178 & 0.382 \\
\hline First consumption quintile $(=1)$ & 0.305 & 0.460 & 0.206 & 0.405 \\
\hline Second consumption quintile (=1) & 0.250 & 0.433 & 0.216 & 0.412 \\
\hline Third consumption quintile $(=1)$ & 0.184 & 0.388 & 0.220 & 0.414 \\
\hline Fourth consumption quintile (=1) & 0.155 & 0.362 & 0.192 & 0.394 \\
\hline Fifth consumption quintile $(=1)$ & 0.105 & 0.307 & 0.164 & 0.378 \\
\hline \multicolumn{5}{|c|}{\begin{tabular}{|c|} 
Household Head Characteristics \\
\end{tabular}} \\
\hline HH head above primary (=1) & 0.308 & 0.462 & 0.321 & 0.467 \\
\hline HH head age & 44.196 & 14.774 & 45.28 & 11.66 \\
\hline HH gender $(=1)$ & 0.774 & 0.418 & 0.747 & 0.434 \\
\hline \multicolumn{5}{|c|}{ Locational Characteristics } \\
\hline Eastern Region (=1) & 0.201 & 0.401 & 0.221 & 0.415 \\
\hline Central Region $(=1)$ & 0.346 & 0.476 & 0.324 & 0.468 \\
\hline Western Region (=1) & 0.181 & 0.385 & 0.198 & 0.399 \\
\hline Mid-western Region (=1) & 0.163 & 0.369 & 0.148 & 0.355 \\
\hline Far-western Region (=1) & 0.109 & 0.312 & 0.108 & 0.310 \\
\hline Rural (=1) & 0.758 & 0.428 & 0.710 & 0.454 \\
\hline $\begin{array}{l}\text { Time taken to reach nearest health facility } \\
\text { more than } 30 \text { minutes }(=1)\end{array}$ & 0.310 & 0.463 & 0.298 & 0.457 \\
\hline \multicolumn{5}{|c|}{ Child's Characteristics } \\
\hline Enrolled in school $(=1)$ & 0.297 & 0.457 & 0.838 & 0.368 \\
\hline Child' age & 2.577 & 1.703 & 14.17 & 2.780 \\
\hline Child's age squared & 9.583 & 8.981 & 208.58 & 0.457 \\
\hline Child is male (=1) & 0.507 & 0.500 & 0.481 & 0.499 \\
\hline Number of Observations & \multicolumn{2}{|c|}{3421} & \multicolumn{2}{|c|}{6830} \\
\hline
\end{tabular}

Source: Nepal Living Standard Survey 2010-2011. CBS, NPC, GoN, 2011. 
Nearly 60 to 66 percent of the children and adolescents self-report that their health status is excellent while 30 to 35 percent report good health status. Less than 1 percent reports that their health status is either fair or poor. More than 75 percent of the households own agricultural land suggesting that many households are located in rural areas. Household consumption per capita ranges between Rs. 30000 and Rs. 37000. Further, disaggregation of the consumption per capita reveals that about 30 percent of the households with children aged 0-5 years belongs to the poorest consumption quintile and this proportion declines as consumption quintile increases. This means higher the consumption quintile, lower the proportion of households. Only 10.5 percent of the households belong to the richest quintile. For the households with adolescents, there is not much variation across the households. About 20 percent of the households each belongs to the first two consumption quintiles, 22 percent in the third consumption quintile, 19.2 percent in the fourth quintile and 16.4 percent in the fifth quintile. On average, there are six household members. Nearly 42 percent of the households belong to the middle caste, 30 to 33 percent are Brahmin and Chettri, 18 to 22 percent are Dalit, Muslim and other castes and rest belongs to other castes.

So far as household head characteristics is concerned, only about 31 percent have attained secondary and higher education; average age is 45 percent; and more than 70 percent are male. Regarding location, majority of the households live in Central Region followed by Eastern Region, Western Region, Mid-western Region and Far-western Region. Likewise, large proportion of people lives in rural areas but within a proximate distance to the nearest health facility. Regarding child's characteristics, 30 percent of the children are enrolled in school. For adolescents, school enrollment is more than 80 percent. The average age of a child is 2.6 years while this is 14 years for the adolescents. Gender proportion is approximately only half.

\section{Results}

Two set of results are presented using regression analysis of equation-1. One for child health status and next is for adolescent health status. In tables 2 and 3, results from the ordered probit model are presented and marginal effects are reported for interpretation. 
Raut \& Karmayogi: An Inquiry into Child Health and ...... 43

Table 2: Regression Results for the Health Determinants of Children Aged 0-5 Years

\begin{tabular}{|c|c|c|c|c|}
\hline \multirow[t]{2}{*}{ Variables } & \multirow{2}{*}{$\begin{array}{l}\text { Health } \\
\text { Status }\end{array}$} & \multicolumn{3}{|c|}{ Marginal Effects } \\
\hline & & Excellent $=1$ & Good = 2 & Fair $=3$ \\
\hline \multicolumn{5}{|c|}{ Household (HH) Characteristics } \\
\hline \multirow[t]{2}{*}{$\mathrm{HH}$ own agriculture land $(=1)$} & $0.164 * *$ & $-0.057 * *$ & $0.053^{* *}$ & $0.004 * *$ \\
\hline & $(0.076)$ & $(0.026)$ & $(0.024)$ & $(0.001)$ \\
\hline \multirow[t]{2}{*}{$\operatorname{Newar}(=1)^{\mathrm{a}}$} & $0.245^{*}$ & $-0.085^{*}$ & $0.079 *$ & $0.005^{*}$ \\
\hline & $(0.128)$ & $(0.044)$ & $(0.041)$ & $(0.003)$ \\
\hline \multirow{2}{*}{$\begin{array}{l}\text { Terai-madhesi and janajati } \\
\text { households (=1) }\end{array}$} & $-0.130 *$ & $0.045^{*}$ & $-0.042 *$ & $-0.003 *$ \\
\hline & $(0.071)$ & $(0.024)$ & $(0.023)$ & $(0.001)$ \\
\hline \multirow{2}{*}{$\begin{array}{l}\text { Dalit, Muslim and other castes } \\
(=1)\end{array}$} & $0.168 * *$ & $-0.058 * *$ & $0.055 * *$ & $0.004^{*}$ \\
\hline & $(0.084)$ & $(0.029)$ & $(0.027)$ & $(0.002)$ \\
\hline \multirow[t]{2}{*}{ First consumption quintile $(=1)^{b}$} & 0.109 & -0.038 & 0.035 & 0.002 \\
\hline & $(0.128)$ & $(0.044)$ & $(0.042)$ & $(0.003)$ \\
\hline \multirow{2}{*}{$\begin{array}{l}\text { Second consumption quintile } \\
(=1)\end{array}$} & -0.041 & 0.014 & -0.013 & -0.001 \\
\hline & $(0.124)$ & $(0.043)$ & $(0.040)$ & $(0.003)$ \\
\hline \multirow[t]{2}{*}{ Third consumption quintile $(=1)$} & 0.0701 & -0.024 & 0.023 & 0.001 \\
\hline & $(0.120)$ & $(0.042)$ & $(0.039)$ & $(0.003)$ \\
\hline \multirow{2}{*}{$\begin{array}{l}\text { Fourth consumption quintile } \\
(=1)\end{array}$} & -0.035 & 0.012 & -0.011 & -0.001 \\
\hline & $(0.111)$ & $(0.034)$ & $(0.036)$ & $(0.003)$ \\
\hline \multirow[t]{2}{*}{ HH size } & $-0.031 * * *$ & $0.011 * * *$ & $-0.010 * * *$ & -0.001 \\
\hline & $(0.012)$ & $(0.004)$ & $(0.004)$ & $(0.000)$ \\
\hline \multicolumn{5}{|c|}{ Household Head Characteristics } \\
\hline \multirow[t]{2}{*}{ HH head age } & 0.001 & -0.000 & 0.000 & 0.001 \\
\hline & $(0.002)$ & $(0.001)$ & $(0.001)$ & $(0.000)$ \\
\hline \multirow[t]{2}{*}{ HH head male $(=1)$} & 0.037 & -0.013 & 0.012 & 0.001 \\
\hline & $(0.070)$ & $(0.024)$ & $(0.023)$ & $(0.001)$ \\
\hline \multirow{2}{*}{$\begin{array}{l}\mathrm{HH} \text { higher than primary level } \\
(=1)\end{array}$} & -0.039 & 0.024 & -0.023 & -0.001 \\
\hline & $(0.077)$ & $(0.029)$ & $(0.027)$ & $(0.001)$ \\
\hline \multicolumn{5}{|c|}{ Child's Characteristics } \\
\hline \multirow[t]{2}{*}{ Child's age } & $-0.029 * *$ & $0.042 * * *$ & $-0.039 * * *$ & $-0.003 * *$ \\
\hline & $(0.042)$ & $(0.014)$ & $(0.013)$ & $(0.001)$ \\
\hline \multirow[t]{2}{*}{ Child's age squared } & $0.022 * *$ & $-0.007^{* *}$ & $0.007 * *$ & $0.005^{* *}$ \\
\hline & $(0.008)$ & $(0.003)$ & $(0.003)$ & $(0.000)$ \\
\hline \multirow[t]{2}{*}{ Current enrollment status $(=1)$} & -0.094 & 0.029 & -0.027 & -0.002 \\
\hline & $(0.071)$ & $(0.023)$ & $(0.021)$ & $(0.001)$ \\
\hline
\end{tabular}




\begin{tabular}{|c|c|c|c|c|}
\hline \multirow[t]{2}{*}{ Child is male $(=1)$} & 0.053 & -0.018 & 0.017 & 0.001 \\
\hline & $(0.044)$ & $(0.015)$ & $(0.014)$ & $(0.001)$ \\
\hline \multicolumn{5}{|c|}{ Locational Characteristics } \\
\hline \multirow[t]{2}{*}{ Eastern Region $=1^{\mathrm{c}}$} & -0.071 & 0.025 & -0.023 & -0.001 \\
\hline & $(0.083)$ & $(0.029)$ & $(0.027)$ & $(0.002)$ \\
\hline \multirow[t]{2}{*}{ Western Region $=1$} & $-0.674 * * *$ & $0.235^{* * *}$ & $-0.219 * * *$ & $-0.016 * * *$ \\
\hline & $(0.099)$ & $(0.033)$ & $(0.032)$ & $(0.003)$ \\
\hline \multirow[t]{2}{*}{ Mid-western Region=1 } & $0.384 * * *$ & $-0.134 * * *$ & $0.125^{* * *}$ & $0.009 * * *$ \\
\hline & $(0.087)$ & $(0.029)$ & $(0.028)$ & $(0.002)$ \\
\hline \multirow[t]{2}{*}{ Far-Western Region $=1$} & $0.287 * * *$ & $-0.100 * *$ & $0.093 * * *$ & $0.007 * *$ \\
\hline & $(0.104)$ & $(0.036)$ & $(0.034)$ & $(0.003)$ \\
\hline \multirow[t]{2}{*}{ Rural (=1) } & -0.079 & 0.028 & -0.026 & -0.002 \\
\hline & $(0.079)$ & $(0.027)$ & $(0.026)$ & $(0.002)$ \\
\hline \multirow{2}{*}{$\begin{array}{l}\text { Time taken to reach to the } \\
\text { nearest health facility more than } \\
30 \text { minutes }(=1)\end{array}$} & -0.0870 & 0.030 & -0.028 & -0.002 \\
\hline & $(0.067)$ & $(0.023)$ & $(0.021)$ & $(0.001)$ \\
\hline Number of Observations & \multicolumn{4}{|c|}{3421} \\
\hline
\end{tabular}

Note: Robust standard errors in parentheses*** $p<0.01, * * p<0.05, * p<0.1$

a: Reference category is Brahmin Chettri;

b: Reference category is the fifth consumption quintile household (richest); c: Reference category is Central Region.

Source: Authors' estimation using NLSS- III.

Table 2 shows that caste, household size, age of the children, and the region of residence have significant effect on health status of the children aged 0-5 years. The probability of Newar children reporting excellent health status is 8.5 percent points lower while that of Dalit, Muslim and other castes children reporting the same is lower by 5.8 percent points, both compared to the children from high caste household i.e. Brahmin and Chettri. But Terai-madhesi and janajati caste households report better health status. The probability of an average child reporting excellent health status increases by 4.2 percent points as the child becomes a year older. However, there is a non-linear relationship between child health status and age indicating that the health status may begin to deteriorate after certain years of age.

Next, the study analyzes whether there exists inequality in health status by region and socio-economic status. The results show that there is a regional disparity in health status while there is no evidence of inequality by socio-economic status of the households. Child health status is worse off in Mid-western and Far-western Regions as compared to the Central Region. The probability of a child living in Mid-west and Far-west Regions reporting excellent health status is lower by about 13 percent and 10 percent than the children living in Central Region. On the other hand, a child in Western Region reports better health status by 24 percent points as compared to the Central Region. 
Raut \& Karmayogi: An Inquiry into Child Health and ...... 45

Table 3: Regression Results for the Health Determinants of Adolescent Aged 10-19 Years

\begin{tabular}{|c|c|c|c|c|}
\hline \multirow{2}{*}{ Variables } & \multirow{2}{*}{$\begin{array}{l}\text { Health } \\
\text { Status }\end{array}$} & \multicolumn{3}{|c|}{ Marginal Effects } \\
\hline & & Excellent $=1$ & Good $=2$ & Fair $=3$ \\
\hline \multicolumn{5}{|c|}{ Household $(\mathrm{HH})$ Characteristics } \\
\hline \multirow[t]{2}{*}{ HH own agriculture land (=1) } & $0.137 * *$ & $-0.046 * *$ & $0.044^{* *}$ & $0.002^{*}$ \\
\hline & $(0.021)$ & $(0.026)$ & $(0.024)$ & $(0.001)$ \\
\hline \multirow[t]{2}{*}{$\operatorname{Newar}(=1)^{\text {a }}$} & 0.073 & -0.025 & 0.024 & 0.001 \\
\hline & $(0.031)$ & $(0.029)$ & $(0.001)$ & $(0.003)$ \\
\hline \multirow[t]{2}{*}{ Terai-madhesi and janajati Caste $(=1)$} & $-0.109 *$ & $0.034^{*}$ & $-0.035^{*}$ & $-0.002 *$ \\
\hline & $(0.058)$ & $(0.019)$ & $(0.019)$ & $(0.001)$ \\
\hline \multirow[t]{2}{*}{ Dalit, Muslim and other castes ( $=1$ ) } & 0.045 & -0.015 & 0.014 & 0.001 \\
\hline & $(0.071)$ & $(0.024)$ & $(0.023)$ & $(0.001)$ \\
\hline \multirow[t]{2}{*}{ First consumption quintile $(=1)^{b}$} & $0.296 * * *$ & $-0.099 * * *$ & $0.095^{* * *}$ & $0.005^{* * *}$ \\
\hline & $(0.097)$ & $(0.032)$ & $(0.031)$ & $(0.002)$ \\
\hline \multirow[t]{2}{*}{ Second consumption quintile $(=1)$} & $0.151^{*}$ & $-0.051^{*}$ & $0.048^{*}$ & 0.003 \\
\hline & $(0.091)$ & $(0.031)$ & $(0.029)$ & $(0.002)$ \\
\hline \multirow{2}{*}{ Third consumption quintile $(=1)$} & 0.108 & -0.036 & 0.034 & 0.002 \\
\hline & $(0.086)$ & $(0.029)$ & $(0.027)$ & $(0.001)$ \\
\hline \multirow[t]{2}{*}{ Fourth consumption quintile $(=1)$} & -0.017 & 0.006 & -0.006 & -0.000 \\
\hline & $(0.079)$ & $(0.027)$ & $(0.025)$ & $(0.001)$ \\
\hline \multirow[t]{2}{*}{ HH size } & $-0.024 * *$ & $0.008 * *$ & $-0.007^{* *}$ & -0.000 \\
\hline & $(0.011)$ & $(0.004)$ & $(0.003)$ & $(0.000)$ \\
\hline \multicolumn{5}{|c|}{ Household Head Characteristics } \\
\hline \multirow[t]{2}{*}{$\mathrm{HH}$ head age } & 0.001 & -0.000 & 0.000 & 0.001 \\
\hline & $(0.002)$ & $(0.001)$ & $(0.001)$ & $(0.000)$ \\
\hline \multirow[t]{2}{*}{ HH head male $(=1)$} & 0.037 & -0.013 & 0.012 & 0.001 \\
\hline & $(0.070)$ & $(0.024)$ & $(0.023)$ & $(0.001)$ \\
\hline \multirow[t]{2}{*}{$\mathrm{HH}$ higher than primary level $(=1)$} & -0.039 & 0.024 & -0.023 & -0.001 \\
\hline & $(0.077)$ & $(0.029)$ & $(0.027)$ & $(0.001)$ \\
\hline \multicolumn{5}{|c|}{ Child's Characteristics } \\
\hline \multirow[t]{2}{*}{ Child's age } & $-0.029 * *$ & $0.042 * * *$ & $-0.039 * * *$ & $-0.003 * *$ \\
\hline & $(0.042)$ & $(0.014)$ & $(0.013)$ & $(0.001)$ \\
\hline \multirow[t]{2}{*}{ Child's age squared } & $0.022 * *$ & $-0.007 * *$ & $0.007^{* *}$ & $0.005^{* *}$ \\
\hline & $(0.008)$ & $(0.003)$ & $(0.003)$ & $(0.000)$ \\
\hline \multirow[t]{2}{*}{ Current enrollment status $(=1)$} & -0.094 & 0.029 & -0.027 & -0.002 \\
\hline & $(0.071)$ & $(0.023)$ & $(0.021)$ & $(0.001)$ \\
\hline Child is male $(=1)$ & 0.053 & -0.018 & 0.017 & 0.001 \\
\hline
\end{tabular}




\begin{tabular}{|c|c|c|c|c|}
\hline & $(0.044)$ & $(0.015)$ & $(0.014)$ & $(0.001)$ \\
\hline \multicolumn{5}{|c|}{ Locational Characteristics } \\
\hline \multirow[t]{2}{*}{ Eastern Region $=1 c$} & -0.071 & 0.025 & -0.023 & -0.001 \\
\hline & $(0.083)$ & $(0.029)$ & $(0.027)$ & $(0.002)$ \\
\hline \multirow[t]{2}{*}{ Western Region=1 } & $-0.674 * * *$ & $0.235^{* * *}$ & $-0.219 * * *$ & $-0.016 * * *$ \\
\hline & $(0.099)$ & $(0.033)$ & $(0.032)$ & $(0.003)$ \\
\hline \multirow[t]{2}{*}{ Mid-western Region=1 } & $0.384 * * *$ & $-0.134 * * *$ & $0.125^{* * *}$ & $0.009 * * *$ \\
\hline & $(0.087)$ & $(0.029)$ & $(0.028)$ & $(0.002)$ \\
\hline \multirow[t]{2}{*}{ Far-Western Region=1 } & $0.287^{* * *}$ & $-0.100 * *$ & $0.093 * * *$ & $0.007 * *$ \\
\hline & $(0.104)$ & $(0.036)$ & $(0.034)$ & $(0.003)$ \\
\hline \multirow[t]{2}{*}{ Rural (=1) } & -0.079 & 0.028 & -0.026 & -0.002 \\
\hline & $(0.079)$ & $(0.027)$ & $(0.026)$ & $(0.002)$ \\
\hline \multirow{2}{*}{$\begin{array}{l}\text { Time taken to reach to the nearest } \\
\text { health facility more than } 30 \text { minutes } \\
(=1)\end{array}$} & -0.0870 & 0.030 & -0.028 & -0.002 \\
\hline & $(0.067)$ & $(0.023)$ & $(0.021)$ & $(0.001)$ \\
\hline Number of Observations & \multicolumn{4}{|c|}{6830} \\
\hline
\end{tabular}

Note: Robust standard errors in parentheses*** $p<0.01,{ }^{* *} p<0.05,{ }^{*} p<0.1$

a: Reference category is Brahmin Chettri;

b: Reference category is the fifth consumption quintile household (richest); c: Reference category is Central Region.

Source: Authors' estimation using NLSS- III.

Table 3 shows that the socio-economic status of the households, adolescent's age, gender, school enrollment status, region and area of residence are major determinants of adolescent's health. An adolescent of the first (poorest) and second consumption quintile are less likely to report excellent health status by about 10 and 5 percent respectively as compared to the one in the richest quintile. The probability of reporting excellent status increases by 1 percent with one additional year of increase in age. An adolescent enrolled in a school are more likely to report excellent health status by 5 percent as compared to those not enrolled in school. In terms of regional disparity, the regression estimates show that an adolescent's health status is better in Eastern and Western Regions but worse in Mid-western and Far-western Regions and all compared to the adolescent's health in the Central Region. Likewise, adolescent residing in rural areas reports excellent health status by 5.3 percent than those in urban areas.

In order to analyze the effect of parental health on child health status, separate regression equations are estimated with all control variables considered in equation (1). This is because parental health is endogenous and is more likely to be correlated with other household characteristics. For brevity, marginal effects of relevant variables are reported in Table 4. 
Table 4: Marginal Effects of Parental Health on Child and Adolescent Health Status

\begin{tabular}{|c|c|c|c|}
\hline \multirow{2}{*}{ Variables } & \multicolumn{3}{|c|}{ Child Health } \\
\cline { 2 - 4 } & Excellent = 1 & Good = 2 & Fair = 3 \\
\hline Father's health & $0.133^{* * *}$ & $-0.115^{* * *}$ & $-0.017^{* * *}$ \\
excellent (=1) & $(0.017)$ & $(0.015)$ & $(0.003)$ \\
\hline Mother's health & $0.379^{* * *}$ & $-0.329^{* * *}$ & $-0.049^{* * *}$ \\
excellent (=1) & $(0.009)$ & $(0.010)$ & $(0.007)$ \\
\hline \multicolumn{3}{|c|}{ Adolescent Health } \\
\hline & Excellent =1 & Good = 2 & Fair = 3 \\
\hline Father's health & $0.261^{* * *}$ & $-0.242^{* * *}$ & $-0.018^{* * *}$ \\
excellent (=1) & $(0.015)$ & $(0.015)$ & $(0.003)$ \\
\hline Mother's health & $0.344^{* * *}$ & $-0.319^{* * *}$ & $-0.024^{* * *}$ \\
excellent (=1) & $(0.013)$ & $(0.013)$ & $(0.003)$ \\
\hline
\end{tabular}

Note: Robust standard errors in parentheses ${ }^{* * *} p<0.01,{ }^{* *} p<0.05,{ }^{*} p<0.1$

Source: Authors' estimation using NLSS -III.

Regression results in Table 4 show that both father's and mother's health status matter for child and adolescent health. A child and an adolescent of a father with excellent health status aremore likely to report better health status by 13.3 and 26.1 percent respectively while the same for a mother with excellent health status is 37.9 and 34.4 percent respectively. It is clearly evident from the given table that mother's health status matter more for the health of their kids.

\section{Comparison and Discussion}

The results show that Dalit and Newar children report poorer health status as compared to the Brahmin and Chettri children. There is, however, no such caste-based disparity in health status of adolescent. Moreover, both Terai-madhesi and janajati children and adolescent report better health status than Brahmin and Chettri in their respective cohorts. This indicates that there is still a caste based disparity in health status particularly among children. Pandey et al., (2013) also shows that other correlates of child health status such as immunization and 'Vitamin-A' coverage, nutritional status and prevalence of anemia are poorer among the Dalit Children. One important reason may be their limited access to healthcare services due to the information constraint and the existence of dogma where Dalits are socially barred to access certain types of public services. Information constraint is more important in this context where some households are less aware about the good practices and service utilization that help improve child health.

It is also observed that the socio-economic status does not determine inequality in health status among children. The former may be due to the fact that the children's health is more 
dependent on other factors than income such as medical care and child rearing, such as antenatal care, attended delivery and breastfeeding. On the contrary, general socio-economic conditions or income matters for the health status of adolescent (Charmarbagwala et al., 2014). On a similar line, Cameron and Williams (2009), Currie and Stabile (2003) and Case, Lubotsky, and Paxson (2002) show that the relationship between socio-economic status and child health become more pronounced for older children. The impact of socio-economic status on child health also depends upon the gender of the income earner in the households and/or of the household head. Several studies in Nepal and elsewhere find that women allocate more resources for the benefit of their children (Charmarbagwala et al., 2014). For example, Allendorf (2007), Malapit et al., (2015), and Mishra and Sam (2016)increasing productivity, and improving welfare. However, little empirical research has evaluated these claims. This paper uses the 2001 Nepal Demographic and Health Survey to explore whether women's land rights empower women and benefit young children's health in Nepal. The results provide support for both of these hypotheses. Women who own land are significantly more likely to have the final say in household decisions, a measure of empowerment.

Similarly, children of mothers who own land are significantly less likely to be severely underweight. (C) 2007 Elsevier Ltd. All rights reserved.","author":[\{"droppingparticle":"","family":"Allendorf","given":"Keera","non-dropping-particle":"","parsenames":false,"suffix":""\}],"container-title":"World Development","id":"ITEM-1","issued":\{ "date-parts":[["2007"]]\},"title":"Do Women's Land Rights Promote Empowerment and Child Health in Nepal?","type":"article-journal"\},"uris":["http://www.mendeley.com/ documents/?uuid=aba6d964-c257-4c2b-bb71-b978b40cb308"]\}, \{"id":"ITEM-2","itemDa ta":\{"DOI":"10.1080/00220388.2015.1018904","ISSN":"17439140","abstract":"Abstract: We use household survey data from Nepal to investigate relationships between women's empowerment in agriculture and production diversity on maternal and child dietary diversity and anthropometric outcomes. Production diversity is positively associated with maternal and child dietary diversity, and weight-for-height z-scores. Women's group membership, control over income, reduced workload, and overall empowerment are positively associated with better maternal nutrition. Control over income is positively associated with height-forage z-scores (HAZ show that women's empowerment by way of land ownership, control over income and women's group membership increase women's bargaining power in Nepal. This in turn increases investment in human capital of the households such as health, education and nutrition as a result of which health outcomes of children are better in such households. In the current study, it can be inferred that household heads are mostly male hence restricting the decision-making power of women in the households. This may also explain why the effects of socio-economic status are insignificant for children.

Regarding regional disparity, it is observed that both the children and adolescents in Midwestern and Far-western Regions demonstrate worst health outcomes as compared to the children in Central Region. This is consistent with the previous studies which show that child under-5 mortality rate, malnutrition and stunting, diarrhea and acute respiratory illness are higher in Mid-western and Far-western Regions (Akhtar, 2015)geographical, and economic setting; Millennium Development Goal \#4 demanded improved infant and child mortality, 
as well as adequate measles vaccine coverage by the year 2015. Research in this report presents progress and direction of child health care policy across more than a decade of time in attempts of attaining MDG \#4 and general child health care advancements. Subsequent observations and suggestions were delineated and offered. Progress since the 1990's up to 2012 was analyzed by review of serial national survey and report data. Trends and variations between regions were mostly analyzed amongst various child health care determinants. Results indicated many improved factors; Nepal will likely achieve MDG regarding child under-5 mortality, but may not achieve measles vaccine coverage or infant mortality goals. Furthermore, severe regional disparities were evident within Nepal, particularly in the Mid and Far-Western regions. A call for integrated community-based primary health care (CBPHC. Notably, however, the coefficients are larger for children than adolescent suggesting that children have poorer health than the adolescents in Mid-western and Far-western

Regions. This means that there is a low level of child-centered health awareness, high cost of access to health service facilities for children than adults, and limited health service facilities specializing on child health in these regions.

The study finds no evidence of the effect of rural residence and distance to the nearest health facility on health status of children. One reason may be the increased availability of pharmacies in rural areas and in proximity to the households. In fact, people are reluctant to visit urban areas and faraway health facilities unless perceived illness is not serious; instead they consult pharmacies for common illness and take medicines prescribed by them. The effect of rural residence and distance to the nearest health facility on adolescent's health status is, however, found to be counterintuitive. The results show that the distant and rural dwellers have better health status.

Finally, the results about the significant impact of parent's health on the health status of children and adolescent are very much in line with the previous studies. For example, Murphey et al., (2018) shows that there is a strong positive association between parent health and child health after controlling for a host of demographic characteristics in the USA. This study further disaggregates parent's health status and finds that mother's health matter more than father's health.

\section{Conclusion and Recommendations}

This study primarily analyzes the determinants of child health 0 to 5 years old and then compares them with the determinants of adolescent health 10-19 years old. The particular focus is to test whether there exists socio-economic inequality and regional disparity in health of children and adolescents. It finds no evidence of socio-economic inequality in child health while such inequality exists in adolescent health. It is argued that factors other than income or socioeconomic status such as medical care, child rearing and breastfeeding matter for child health. However, the study finds regional disparity in health status: children and adolescents living in Mid-western and Far-western Regions have worse health outcomes. In addition, the study exhibits higher disparity among children than adolescents. This difference may be attributed to the low-level of child-centered health awareness, high cost of access to 
health service facilities, and limited health service facilities specializing on child health in these regions. In addition, it is also found that caste, age of children, school enrollment status and parental health status are significantly associated with child and adolescent health status. Further, disaggregation of parental health status reveals that mother's health status matter more for the health status of both the child as well as adolescent.

Given findings of the research, the study proposes following set of recommendations. In the short term, it is important to strengthen child health service coverage (especially immunization, hygiene awareness, breast feeding practices, intensive door to door pre and post-natal care, etc.) for children of 0-5 years. It is also better if some financial incentive is provided to the low-caste household so that they can utilize health service facilities without having to bear high out of pocket expenditure. It is also advisable to strongly monitor the ongoing programs targeted at child health to ensure that they are effectively and adequately implemented. In the medium term, government should invest on health infrastructure and technology with a particular focus on Mid-western and Far-western Regions. Not only health infrastructure, but the Government has to ensure that adequate work forces are incentivized to go and work in these regions. The presence of private sector in health is also poor in these regions. It is, therefore, important to create an environment conducive for private sector to invest in the less-developed regions of the country. In the long term, universal health insurance has to be introduced where all the citizens of the country can have an access to all kind of health services without incurring huge financial burden. In this regard, it may also be good to revisit the current public health insurance plan introduced recently in some districts. Without improving the quality of health infrastructure together with qualified and motivated workforce providing quality health service (medium term solution), it is difficult to increase the take up of the health insurance.

\section{References}

Aitchison, J., \& Silvey, S. D. (1957). The generalization of probit analysis to the case of multiple responses. Biometrika. https://doi.org/10.2307/2333245

Akhtar, R. (2015). Child healthcare in Nepal: Progress and direction. American Journal of Public Health Research, 3(2), 74-80. https://doi.org/10.12691/ajphr-3-2-7

Allendorf, K. (2007). Do women's land rights promote empowerment and child health in Nepal? World Development. https://doi.org/10.1016/j.worlddev.2006.12.005

Apouey, B., \& Geoffard, P. Y. (2013). Family income and child health in the UK. Journal of Health Economics. https://doi.org/10.1016/j.jhealeco.2013.03.006

Cameron, L., \& Williams, J. (2009). Is the relationship between socioeconomic status and health stronger for older children in developing countries? Demography. https://doi. org/10.1353/dem.0.0054

Case, A., Lubotsky, D., \& Paxson, C. (2002). Economic status and health in childhood: The origins of the gradient. American Economic Review. https://doi. 
org/10.1257/000282802762024520

CBS (Central Bureau of Statistics) (2011). Nepal Living Standards Survey-2010/11. Kathmandu, Nepal. Retrieved from http://siteresources.worldbank.org/INTLSMS/ Resources/3358986-1181743055198/3877319-1329489437402/Statistical_Report_ Vol1.pdf

Charmarbagwala, R., Ranger, M., Waddington, H., \& White, H. (2014). The determinants of child health and nutrition: A meta-analysis (No. 82087). Washington DC, World Bank Group.

Contoyannis, P., \& Dooley, M. (2010). The role of child health and economic status in educational, health, and labour market outcomes in young adulthood. Canadian Journal of Economics. https://doi.org/10.1111/j.1540-5982.2009.01574.x

Crosby, R. A., Santelli, J. S., \& DiClemente, R. J. (2009). Adolescents at risk: A generation in jeopardy. In Adolescent Health: Understanding and Preventing Risk Behaviors.

Currie, J., \& Stabile, M. (2003). Socioeconomic status and child health: Why is the relationship stronger for older children? American Economic Review. https://doi. org $/ 10.1257 / 000282803322655563$

De Maio, J. A., Zubrick, S. R., Silburn, S. R., Lawrence, D. M., Mitrou, F. G., Dalby, R. B., ... Cox, A. (2005). The western Australian aboriginal child health survey: Measuring the social and emotional wellbeing of aboriginal children and intergenerational effects of forceds separation. The Medical journal of Australia.

Greene, W. H., \& Hensher, D. A. (2009). Modeling ordered choices. Unpublished manuscript. https://doi.org/10.1037/0021-9010.91.1.97

Harrington, C., \& Estes, C. L. (2007). Health policy: crisis and reform in the US health care delivery system (Fifth). Boston: Jones and Bartlett Publishers. https://doi. org/10.1177/089033449501100228

Khadka, K. B., Lieberman, L. S., Giedraitis, V., Bhatta, L., \& Pandey, G. (2015). The socio-economic determinants of infant mortality in Nepal: Analysis of Nepal demographichHealth survey, 2011. BMC Pediatrics. https://doi.org/10.1186/s12887015-0468-7

Khanam, R., Nghiem, H. S., \& Connelly, L. B. (2009). Child health and the income gradient: Evidence from Australia. Journal of Health Economics. https://doi.org/10.1016/j. jhealeco.2009.05.001

Kruk, K. E. (2013). Parental income and the dynamics of health inequality in early childhood Evidence from the UK. Health Economics (United Kingdom). https://doi.org/10.1002/ hec. 2876

Lamichhane, R., Zhao, Y., Paudel, S., \& Adewuyi, E. O. (2017). Factors associated with infant mortality in Nepal: A comparative analysis of Nepal demographic and health surveys 
52 | The Economic Journal of Nepal (Issue No. 149)

(NDHS) 2006 and 2011. BMC Public Health, 17(1), 1-18. https://doi.org/10.1186/ s12889-016-3922-z

Li, J., McMurray, A., \& Stanley, F. (2008). Modernity's paradox and the structural determinants of child health and well-being. Health Sociology Review. https://doi. org/10.5172/hesr.451.17.1.64

Malapit, H. J. L., Kadiyala, S., Quisumbing, A. R., Cunningham, K., \& Tyagi, P. (2015). Women's empowerment mitigates the negative effects of low production diversity on maternal and child nutrition in Nepal. Journal of Development Studies. https://doi.or $\mathrm{g} / 10.1080 / 00220388.2015 .1018904$

McKelvey, R. D., \& Zavoina, W. (1975). A statistical model for the analysis of ordinal level dependent variables. The Journal of Mathematical Sociology. https://doi.org/10.1080 /0022250X.1975.9989847

Mishra, K., \& Sam, A. G. (2016). Does women's land ownership promote their empowerment? empirical evidence from Nepal. World Development. https://doi.org/10.1016/j. worlddev.2015.10.003

Murphey, D., Cook, E., Beckwith, S., \& Belford, J. (2018). The health of parents and their children: A two-generation inquiry - child trends. Child Trends, (October), 1-26. Retrieved from https://www.childtrends.org/publications/the-health-of-parents-andtheir-children-a-two-generation-inquiry

Pandey, J. P., Dhakal, M. R., Karki, S., Poudel, P., \& Pradham, M. S. (2013). Maternal and child health in Nepal: The effects of caste, ethnicity, and regional identity. DHS further analysis reports No. 73. Retrieved from http://dhsprogram.com/pubs/pdf/ FA73/FA73.pdf

Propper, C., Rigg, J., \& Burgess, S. (2007). Child health: Evidence on the roles of family income and maternal mental health from a UK birth cohort. Health Economics. https://doi.org/10.1002/hec. 1221

Reinhold, S., \& Jürges, H. (2012). Parental income and child health in Germany. Health Economics. https://doi.org/10.1002/hec.1732

Sah, N. (2004). Determinants of child malnutrition in Nepal: A case analysis from Dhanusha, central Terai of Nepal. Journal of Nepal Health Research Council.

Sreeramareddy, C. T., Harsha Kumar, H. N., \& Sathian, B. (2013). Time trends and inequalities of under-five mortality in Nepal: A secondary data analysis of four demographic and health surveys between 1996 and 2011. PLOS ONE. https://doi.org/10.1371/journal. pone. 0079818

Suwal, J. V. (2001). The main determinants of infant mortality in Nepal. Social Science and Medicine. https://doi.org/10.1016/S0277-9536(00)00447-0

Thapa, B., Powell, J., Yi, J., McGee, J., Landis, J., Rein, L., ... Karmacharya, B. (2017). 
Adolescent health risk and behavior survey: A school based survey in central Nepal. Kathmandu University Medical Journal.

The World Bank. (2007). Healthy Development: The World Bank Strategy for Health, Nutrition and Population Results. The World Bank, Washington D.C. https://doi. org/10.1596/978-0-8213-7193-0

Tiwari, R., Ausman, L. M., \& Agho, K. E. (2014). Determinants of stunting and severe stunting among under-fives: Evidence from the 2011 Nepal Demographic and Health Survey. BMC Pediatrics. https://doi.org/10.1186/1471-2431-14-239

WHO (World Health Organization) (2005). Nutrition in adolescence-issues and challenges for the health sector. WHO Discussion Papers on Adolescence. https://doi.org/10.1142/ S0217751X10048524 